Correction

\title{
Thompson, W.A. et al. Decimative Multiplication of Entropy Arrays, with Application to Influenza. Entropy, 2009, 11, 351-359
}

\author{
William A. Thompson ${ }^{1}$, Andy Martwick ${ }^{2}$ and Joel K. Weltman ${ }^{3, *}$ \\ ${ }^{1}$ Division of Applied Mathematics and Center for Computational Molecular Biology, Brown \\ University, Providence, RI 02912, USA; E-mail: william_thompson_1@brown.edu \\ 2 Department of Physics, Portland State University, Portland, OR 97207, USA; \\ E-mail: martwick@pdx.edu \\ ${ }^{3}$ Department of Medicine, Alpert Medical School of Brown University, Providence, RI 02912, USA \\ * Author to whom correspondence should be addressed; E-mail: joel_weltman@brown.edu
}

Received: 6 August 2009 / Published: 7 August 2009

The sentence sixth line from the end of paragraph two on page 355, "The second synonymous mutation was another $\mathrm{G}=>\mathrm{A}$ transition at position 600 that converted the CAG codon to CAA, without change of encoded amino acid." [1] should be corrected to: "The second synonymous mutation was another $\mathrm{G}=>\mathrm{A}$ transition, at position 600 that converted the GCG codon to GCA, without change of encoded amino acid (ALA).”

Correction of this error does not have a substantive effect on the paper. The correlation between substitutions at nucleotide positions 492 and 600 is unchanged as is the invisibility of these correlated synonymous mutations at the amino acid level. However, we would like the correction made to the accurate identification of the involved codon and I apologize for the inconvenience.

\section{References}

1. Thompson, W.A.; Martwick, A.; Weltman, J.K. Decimative Multiplication of Entropy Arrays, with Application to Influenza. Entropy 2009, 11, 351-359.

(C) 2009 by the authors; licensee Molecular Diversity Preservation International, Basel, Switzerland. This article is an open-access article distributed under the terms and conditions of the Creative Commons Attribution license (http://creativecommons.org/licenses/by/3.0/). 